\title{
Chemistry of the Vitamins
}

\section{VITAMIN A}

$\mathrm{S}$ NCE vitamin A has not yet been isolated, methods for the production of highly active concentrates are of interest. A method of comparing the richness in vitamin $A$ of various products is the so-called 'blue value'. This is the number of blue units read with a Lovibond tintometer for $0.04 \mathrm{gm}$. of solid dissolved in anhydrous chloroform imme. diately after reaction with a solution of antimony trichloride in chloroform. Previous workers have prepared vitamin A concentrates by vacuum distilla. tion, and very active materials had blue values of about 100,000-usually lower.

An adsorption method of concentration has now been investigated by $\mathrm{H}$. N. Holmes, H. Cassidy, R. S. Manly and E. R. Hartzler ${ }^{1}$. The non-saponifiable portion of halibut liver oil was obtained in solution in pentane, the cholesterol and other impurities were frozen out by cooling for 7-10 days in a bath of solid carbon dioxide and alcohol, and filtered off under pressure, or by suction, through carbon dioxide snow. Solutions of 45,000-50,000, in one case 60,000 , blue values were thus obtained. Filtration through an absorption column of Norit oxygen-freed charcoal, with special precautions to prevent oxidation, followed by a column of a now type of magnesia prepared from the precipitated hydroxide, gave blue values of $100,000-140,000$, so that a concentrate of vitamin A at least 40 per cent more potent than any previously recorded was obtained.

\section{VITAMIN $B_{1}$}

By cleavage of vitamin $B_{1}$ with sulphite, a basic substance, $\mathrm{C}_{6} \mathrm{H}_{9} \mathrm{NSO}$, is obtained as a colourless oil giving crystalline hydrochloride, chloroplatinate, picrate and picrolonate. E. R. Buchman, R. R. Williams and J. C. Keresztesy ${ }^{2}$ now find that this substance gives on oxidation an acid with the formula $\mathrm{C}_{4} \mathrm{H}_{4} \mathrm{NS}$.COOH, which is identical with one obtained by Windaus directly from the vitamin. The basic sub. stance is regarded as a tertiary heterocyclic base with a $\beta$-hydroxyethyl side chain, $\mathrm{C}_{4} \mathrm{H}_{4} \mathrm{NS} \mathrm{CH}_{2} \mathrm{CH}_{2} \mathrm{OH}$, and the vitamin itself as a quaternary salt of the base.

The presence of a quaternary nitrogen in the vitamin $B_{1}$ has been confirmed by electrometric titration with alkali by R. R. Williams and A. E. Ruehle ${ }^{3}$, when the presence of a moderately strong basic nitrogen was revealed, too strong for a tertiary base, but not strong enough for a true quaternary base. The basic eleavage product, $\mathrm{C}_{6} \mathrm{H}_{9} \mathrm{NSO}$, behaved as a typical tertiary base, but its methiodide closely resembled the vitamin not only in basic strength but also in exhibiting an unusual pseudo-basic behaviour, both substances requiring an additional equivalent of alkali for complete liberation of the base.

It had been suggested that the vitamin contains a thiazole nucleus, and titrations of some thiazole derivatives gave similar results. The conclusion is reached that vitamin $B_{1}$ contains two basic groups, one of which is of the same order of strength as the nitrogen in the quaternary salt of its basic cleavage product and in 4-methylthiazole ethiodide. This feature of the structural formula for vitamin B proposed by Williams ${ }^{4}$ is thus confirmed.

In view of the presence of sulphur in the vitamin $B_{1}$ molecule, and the suggestion that it contains a thiazole nucleus, it was obviously of interest to examine the mode of combination of the sulphur by methods recently developed for the study of sulphur in proteins, especially the behaviour towards alkali plumbite and bromine water. The vitamin $B_{1}$ and its basic cleavage product behaved very differently with both reagents, according to $H$. T. Clarke and S. Gurin ${ }^{5}$, the vitamin giving lead sulphide relatively rapidly with plumbite reagent and the cleavage product scarcely reacting, and the latter is largely oxidised to sulphuric acid by bromine water under conditions in which the vitamin remains almost unchanged.

These results indicate that the sulphur atom in the base is linked to two carbon atoms in a structure in which the carbon groupings are more susceptible to oxidative attack than is sulphur. The acid obtained by Windaus, $\mathrm{C}_{5} \mathrm{H}_{5} \mathrm{O}_{2} \mathrm{NS}$ (see above), yields lead sulphide with plumbite, yet is resistant to oxida. tion with nitric acid. This is characteristic of the thiazole nucleus, and it is now shown, by synthesis, that the acid is 4-methylthiazole 5-carboxylic acid. The basic cleavage product is shown to be 4-methyl 5- $\beta$-hydroxyethylthiazole, which has been synthesised. Titrations of vitamin hydrochloride and of 4-methyl thiazole ethiodide indicate that the last of the three equivalents of alkali used, reacting about $p \mathrm{H} 9$, opens the thiazole ring with formation of a sulphydryl compound.

Examination of absorption spectra by A. E. Ruehle shows that the ultra-violet absorption of the basic cleavage product of vitamin $B_{1}$ is not only similar to that of the thiazoles, but its derivatives also exhibit absorption similar to that of corresponding thiazole derivatives.

\section{Vitamin C}

The titration curves and dissociation constants of $l$-ascorbic acid (vitamin C) were determined by Birch and Harris ${ }^{7}$, who found at $16^{\circ}-18^{\circ}$ the values $p K_{a_{1}}=4 \cdot 17$ and $p K_{a_{2}}=11 \cdot 57$. A determination at $22^{\circ}-23^{\circ}$ by W. D. Kumler and T. C. Daniels ${ }^{8}$ is now shown to give the values $p K_{a_{1}}=4 \cdot 12$ and $p K_{a_{2}}=$ $11 \cdot 51$, in very good agreement. The hydrogen electrode was used. Titration curves for $l$-ascorbic acid and diethyl dihydroxymaleate in alcohol water solution were also determined, in view of the suggested formula for $l$-ascorbic acid in which this compound has no carboxyl group, but contains a grouping

$$
\cdot \dot{C} \cdot \mathrm{C}(\mathrm{OH})=\mathrm{C}(\mathrm{OH}) \cdot \mathrm{C}_{\mathrm{O}-}^{\mathrm{O}}
$$

Evidence that a structure of this type may give rise to relatively strong acid properties has been cited.

The $\beta$-ketonic ester, diethyldihydroxymaleate, contains this structure, and a consideration of its groups shows that it should be a stronger acid than $l$-ascorbic acid. Actually $l$-ascorbic acid is much 
stronger, its first dissociation constant being a thousand times as great as that of the other compound. The apparent inability of the enolised $\alpha$-hydroxy- $\beta$-ketonic ester type of compound to account for the acid properties of $l$-ascorbic acid suggests that some other grouping is responsible for its large first dissociation constant. It may, however, be suggested that the use of the ordinary hydrogen electrode with a compound containing a double bond requires further investigation.

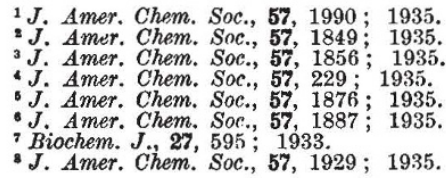

\section{Fire Resistance of Buildings}

A LABORATORY of an unusual kind was opened by H.R.H. the Duke of Kent at the end of last month. This is the Fire Testing Station erected at Elstree by the Fire Offices Committee, an organisation representing the tariff insurance companies, for the purpose of investigating the resistance to fire of building materials and elements of structure.

The need of such an institution has been apparent for some years, and has been steadily growing. Little enough is known of the protection against fire afforded by the traditional types of building material, and still less of the many new types which have appeared in recent years. This uncertainty is reflected in the building codes issued by local authorities, which, so far as provisions against fire are concerned, are often contradictory.

A good deal of research has been carried out abroad, notably at the Underwriters Laboratory at Chicago; and in Great Britain, before and during the Great War, the now defunct British Fire Prevention Com. mittee investigated certain aspects of the problem. But the first attempt in Great Britain to put the whole subject on a sound basis was taken by the British Standards Institution in 1932. In this year, it published "Definitions for the Fire Resistance, Incombustibility and Non-Inflammability of Building Materials and Structures" (B.S.S. No. 476), which laid down a test procedure for assessing the fire resistance of structural elements by means of a standard test upon full-sized specimens.

From the evidence of actual fires and from demonstration tests, it has been established that the tem. perature within a fiercely burning building rises rapidly to about $1,500^{\circ} \mathrm{F}$. and thereafter more slowly up to a maximum of about $2,007^{\circ} \mathrm{F}$. The standard test provides that specimens shall be heated in accordance with a time-temperature curve which approximates to that of recorded conflagrations; furnace temperatures of $1,000^{\circ} \mathrm{F} ., 1,700^{\circ} \mathrm{F}$. and $2,300^{\circ} \mathrm{F}$. are required at the expiration of 5 minutes, 1 hour and 8 hours respectively from the beginning of the test. It is also necessary to take account of the effect of water from fire hoses impinging on a heated structure. The specification therefore requires that immediately following the period of heating the specimen shall be subjected to a jet from a fire hose applied under standardised conditions for a period equal to one minute for each hour of fire exposure. In the case of load-bearing structures, it is further provided that a load equal to $1 \frac{1}{2}$ times the working load shall be maintained on the specimen throughout the whole period of the test. In certain cases, the load must be re-applied forty-eight hours after the completion of firing.
According to the period which elapses between the beginning of the test and the failure of the specimen, the specimen is classified into one of five grades, the highest being represented by a fire-resistance period of six hours and the lowest by one of half an hour.

In the case of walls, floors and other elements which function as separating structures, the specimen is heated on one side only, and failure is indicated either by a temperature rise on the unexposed face of more than $250^{\circ} \mathrm{F}$., or by the development of cracks through which flame can pass, or by collapse under load. Columns and other elements which serve only as load bearers are heated on all sides and are said to have failed when collapse under load occurs.

By issuing this specification, the British Standards Institution not only provided a clear basis for the study of the subject, but also directed attention to the absence of adequate testing facilities. As a result of a conference between interested bodies, the Fire Offices Committee undertook to provide these facilities and the Department of Scientific and Industrial Research to assist in the solution of technical problems.

The Testing Station at Elstree consists of two buildings : one contains equipment for testing the fire-resistance of structural elements; in the other, provision is made for continuing the work on sprinklers, fire-extinguishers and other appliances which has hitherto been carried out by the Committee at Manchester. For testing structural elements, three units have been provided-for walls, columns and floors respectively. In each case, heat is provided by a gas-burning furnace operated electrically from a control room adjoining and overlooking the main building. The gas-air mixture is fed to the burners through 'inspirators' which automatically maintain a constant proportion of the two ingredients at all pressures ; the air is supplied at a maximum pressure of approximately 15 in. of water and the gas at the normal pressure of the mains. The fuel supplied to different parts of the furnace is controlled separately, with the view of maintaining a uniform temperature over the whole area of the specimen.

Both furnace and specimen temperatures are recorded by thermocouples connected to instruments located in the control room. Platinum rhodium platinum couples are used for furnace temperatures, and chromel-alumel or copper-constantan couples for specimen temperatures. The leads from each separate equipment pass through a bus-board mounted on the instrument panel, by means of which a quick change-over may be effected from one furnace to another. 